\title{
A study of fetomaternal outcomes in cases of jaundice at a tertiary care centre
}

\author{
Meena N. Satia, Madhavi Jandhyala*
}

\begin{abstract}
Department of Obstetrics and Gynaecology, Seth G. S. Medical College and K. E. M. Hospital, Mumbai, Maharashtra,
\end{abstract} India

Received: 21 May 2016

Accepted: 11 June 2016

\section{*Correspondence:}

Dr. Madhavi Jandhyala,

E-mail: jmadhavi136@gmail.com

Copyright: (C) the author(s), publisher and licensee Medip Academy. This is an open-access article distributed under the terms of the Creative Commons Attribution Non-Commercial License, which permits unrestricted non-commercial use, distribution, and reproduction in any medium, provided the original work is properly cited.

\section{ABSTRACT}

Background: Jaundice in pregnancy is affects a small percentage of pregnant women yet takes a major toll on the health of both the mother and the foetus. The distribution of jaundice in pregnancy varies throughout the world but is seen comparatively more in the developing countries. The course and outcome of liver disorders in pregnancy is altered due to the various hemodynamic, immunological and hormonal changes of pregnancy.

Methods: This is a retrospective study conducted in the department of obstetrics and gynecology at Seth G.S. medical college and KEM hospital, Mumbai, Maharashtra, India over one year from January to December 2015. Data of 55 women diagnosed to have jaundice from clinical and biochemical evidences as per records was collected.

Results: There were 6780 deliveries; the incidence of jaundice being $0.81 \%$. Most common cause identified was viral hepatitis 34 cases (62\%), 24 cases being hepatitis E, followed by cholestasis of pregnancy 13 cases (23.6\%) and the rest 8 cases were due to other causes like leptospirosis, malaria, HELLP syndrome, drug induced and chronic liver disease due to portal hypertension. $72.7 \%$ belonged from the rural set up. 45 patients were referred from peripheral hospitals. Maximum patients were primigravidas and were between the age group 25-29 years of age. $70 \%$ babies were low birth weight. 50\% babies had intrauterine growth restriction. There were 12 maternal deaths, 7 due to hepatitis E. Total vaginal deliveries were 37, 9 patients underwent lower segment caesarean section and 1 patient had instrumental (vacuum) delivery. Most common maternal complication was DIC and postpartum haemorrhage. 18 patients required ICU care, out of which 13 patients were Hepatitis E positive. Ventilator support was required in $73 \%$ of the patients admitted to the intensive care unit.

Conclusions: Prompt diagnosis, accurate evaluation and a multidisciplinary approach is needed to tackle this high risk pregnancy as it leads to a poor maternal and perinatal outcome.

Keywords: Jaundice, Hepatitis E, Perinatal outcome

\section{INTRODUCTION}

The word "jaundice" is derived from the French word "jaune" meaning yellow. Jaundice is defined as yellowish discoloration of skin and sclera due to increase in serum bilirubin levels.

Pregnancy is characterized by number of physiological changes in various organs including liver. High levels of serum estrogen and progesterone affect the metabolic, synthetic, and excretory function so of the liver during pregnancy. Hence, the course of both acute and chronic liver disease and the feto maternal outcome is altered due to the various hemodynamic, immunological and hormonal changes of pregnancy. Physical findings like spider angiomas and palmar erythema seen in cases of liver disease may be normally seen in pregnancy due to the high estrogen levels. Liver disorders complicate 3-5\% of pregnancies and constitute an important cause of neonatal and maternal morbidity and mortality. ${ }^{1}$ It accounts for $60 \%$ perinatal and $14 \%$ of maternal mortality. $^{2}$ 
Jaundice in pregnancy can be classified into three broad categories.

- Intercurrent in pregnancy or those that are exacerbated in pregnancy: viral hepatitis, drug induced hepatitis

- Pregnancy specific disorders: cholestasis of pregnancy, acute fatty liver of pregnancy, pre eclampsia and HELLP syndrome

- Preexisting liver disorders that take a fulminant course in pregnancy: cirrhosis of liver, chronic hepatitis

The incidence of jaundice in pregnancy varies throughout the world. It is around $0.1 \%$ in developed countries and ranges from $3-20 \%$ or higher in developing countries. Incidence of jaundice in pregnancy is $0.4-0.9 / 1000$ in India. $^{2}$ Viral hepatitis is the most common cause of jaundice in pregnancy followed by cholestasis. The most common viruses responsible for viral hepatitis are hepatitis A (HAV), hepatitis B (HBV), hepatitis C (HCV), hepatitis E virus (HEV). Jaundice is the most common symptom of acute hepatitis. In developing countries like India, hepatitis $\mathrm{E}$ is the commonest cause of fulminant hepatic failure in pregnancy, mostly occurring in the third trimester of pregnancy leading to high maternal mortality ranging from $15-45 \%$. $^{3}$

Since arriving at a correct diagnosis is of utmost importance to save the lives of the mother and the fetus, this study was performed as an attempt to study the various causes of jaundice in pregnancy and its effect on the maternal and fetal outcome.

\section{METHODS}

This is a retrospective study conducted in the department of obstetrics and gynecology at Seth G.S. medical college and KEM hospital, Mumbai, Maharashtra, India over a period of one year from January to December 2015. Clearance to perform the study was taken from the institutional ethics committee at KEM hospital. All pregnant women admitted in our institution as diagnosed cases of jaundice and those with pre-existing liver disease exacerbated during pregnancy were included in the study. A systematic approach to the diagnosis depending upon the presenting symptomatology was made at the onset of the disease.

All the patients were assessed thoroughly by both clinical examination and investigations in the form of complete blood count, liver function tests (including total serum bilirubin with direct and indirect component, SGOT, SGPT and alkaline phosphatase), coagulation profile, renal function tests (serum creatinine, BUN). Viral markers for hepatitis such as IgM HAV antibody, HBV (HBsAg, HBeAg, anti-HBe), HCV (anti-HCV antibody), HEV antibody ( $\operatorname{IgM})$ were done in all patients. The above data was collected, scrutinized for the clinical and biochemical profile, aetiology, maternal outcome and foetal outcome. Advice from internal medicine and gastroenterology department was taken for better and comprehensive management of the patients. Critically ill patients were managed in intensive care unit.

\section{RESULTS}

There were 6780 deliveries conducted in the year 2015, out of which 55 women were admitted as diagnosed cases of jaundice; the incidence of jaundice being $0.81 \%$. Most common cause identified was viral hepatitis 34 cases (62\%), followed by cholestasis of pregnancy 13 cases $(23.6 \%)$ and the rest 8 cases were due to other causes like leptospirosis, malaria, HELLP syndrome, Gilbert's syndrome, AKT induced hepatitis and chronic liver disease due to portal hypertension. ${ }^{1,2}$ This is shown in Figure 1. Out of the 34 cases of viral hepatitis, 24 cases (74\%) cases were due to hepatitis E.

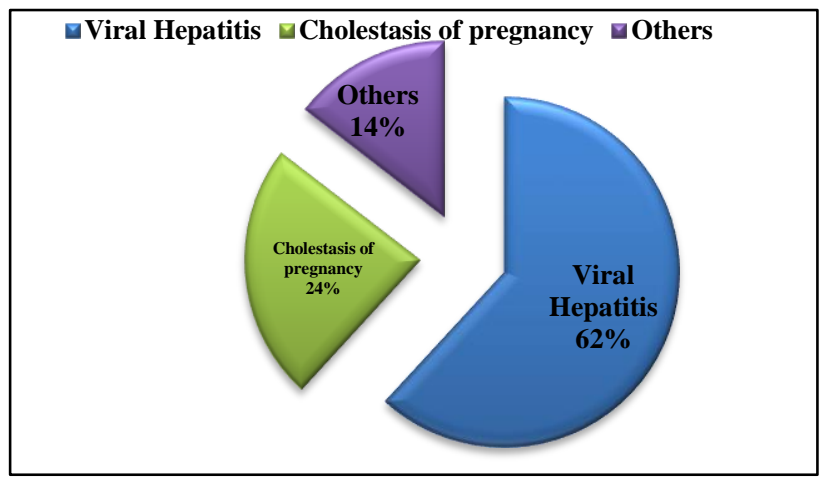

Figure 1: Causes of jaundice.

Table 1: Age distribution, gravidity and referral area of patients.

\begin{tabular}{|lll|}
\hline Age/gravidity & Number of patients & Percentage \\
\hline$<=20$ & 7 & $12.7 \%$ \\
\hline $21-24$ & 15 & $27.2 \%$ \\
\hline $25-29$ & 25 & $45.4 \%$ \\
\hline $30-34$ & 4 & $7.2 \%$ \\
\hline$>=35$ & 4 & $7.2 \%$ \\
\hline Primigravida & 27 & $49 \%$ \\
\hline Multigravida & 26 & $47.3 \%$ \\
\hline Post-partum & 2 & $3.7 \%$ \\
\hline & Referral area & \\
\hline Rural area & 40 & $72.7 \%$ \\
\hline Urban area & 15 & $29.3 \%$ \\
\hline
\end{tabular}

Out of the 55 patients, 40 patients $(72.7 \%)$ belonged from the rural area and $15(29.3 \%)$ from the urban set up. 10 patients were registered and the other 45 were referred during emergency from other peripheral hospitals. This is because most of the patients were from rural area and from lower socioeconomic class where probably the importance of antenatal registration and visits is not well established. Table 1 shows the age distribution among the patients. $45.4 \%$ of the patients belonged to the age group 
of 25-29 years of age. This could also be due to the fact that most of the reproductive women in our set up belong to this age group.

There was no significant difference seen in the affection of jaundice to gravidity. $49 \%$ of patients were primigravidas and $47 \%$ patients were multigravidas, as depicted in Table 1. Two patients that were postpartum cases of jaundice were referred from other hospitals after delivery.

In our study, maximum patients $(43.6 \%)$ belonged to 32-37 weeks of gestation (Figure 2).

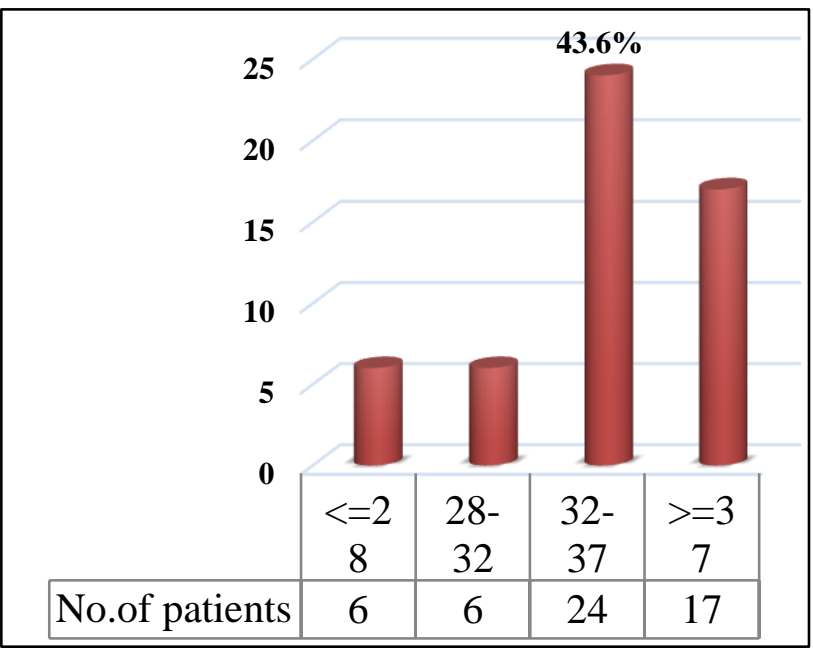

Figure 2: Most common gestational age affected by jaundice.

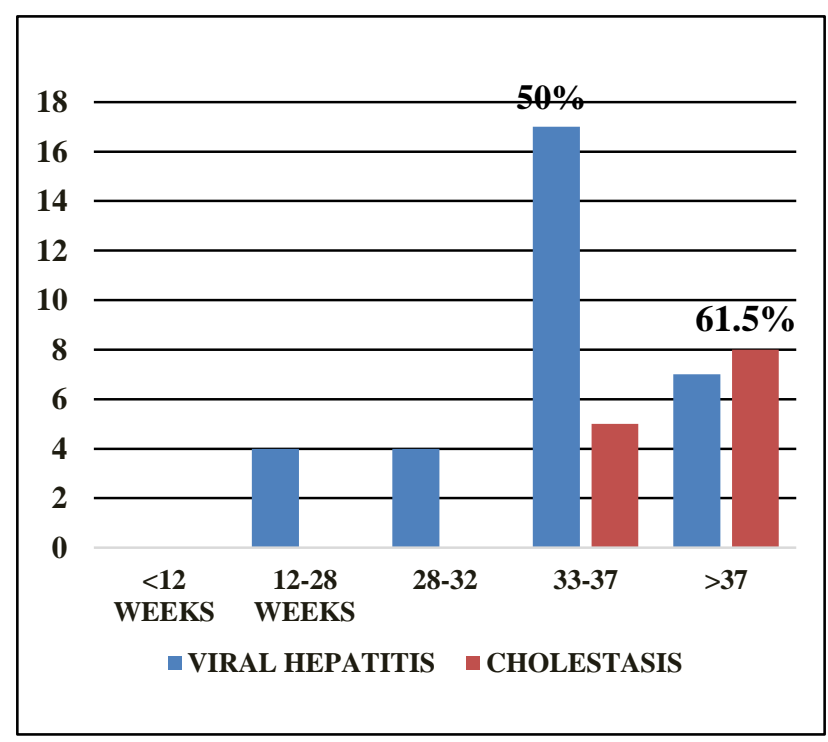

Figure 3: Most common gestational ages affected by hepatitis $\mathbf{E}$ and cholestasis.

Study done by Aparajita et al showed incidence of $52.9 \%$ in younger age group and $51 \%$ were primigravidas. ${ }^{4}$ It is clearly evident from Figure 3 that cholestasis is seen only after 32 weeks of gestation as $61.5 \%$ cases after 37 weeks. $50 \%$ cases of viral Hepatitis were seen between 33-37 weeks of gestation.

Table 2: Presenting complaints.

\begin{tabular}{|lll|}
\hline Complaints & Number & Percentage \\
\hline $\begin{array}{l}\text { Yellowish discoloration of } \\
\text { urine and sclera with fever, } \\
\text { abdominal pain and myalgia }\end{array}$ & 32 & $58 \%$ \\
\hline Pruritus & 17 & $31 \%$ \\
\hline $\begin{array}{l}\text { Deranged LFTs on routine } \\
\text { examination }\end{array}$ & 9 & $16 \%$ \\
\hline Encephalopathy & 8 & $14 \%$ \\
\hline $\begin{array}{l}\text { Bleeding oesophageal } \\
\text { varies, ascites }\end{array}$ & 2 & $1 \%$ \\
\hline
\end{tabular}

Table 2 shows the common complaints with which the patients presented to our institution. Maximum patients (58\%) had complaints of yellowish discoloration of urine and sclera with fever, abdominal pain and myalgia, followed by pruritus (31\%), and others like deranged liver function tests on routine testing, encephalopathy $(14 \%)$ and ascites $(1 \%)$.

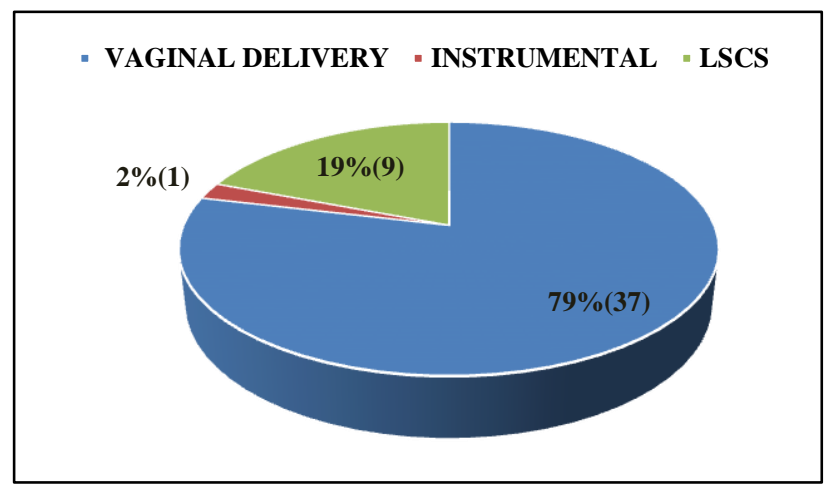

Figure 4: Mode of delivery.

Out of the 55 patients, total vaginal deliveries were 37,9 patients underwent lower segment caesarean section and 1 patient had instrumental (vacuum) delivery. Ten patients required induction of labour; 3 patients for intrahepatic cholestasis at term, 2 for eclampsia with HELLP, 3 for intrauterine foetal death, 2 for severe IUGR. Out of the 9 caesarean sections, 3 were elective sections and 6 were for emergency sections for obstetric indications ( 5 for foetal distress and one for previous LSCS with couple not willing for vaginal birth after caesarean section). Graphical data is shown below in Figure 4.

Table 3 shows the perinatal outcome in our study. Low birth weight babies were $70 \%, 50 \%$ babies had intrauterine growth restriction. It is clearly evident that jaundice leads to poor perinatal outcome. 24 patients $(51 \%)$ delivered between $32-37$ weeks of gestation as shown in Figure 5. It can be said that jaundice causes preterm deliveries and hence contributing to the low birth weight infants. 
Totally five women died undelivered. Two were cases of Hepatitis E with severe coagulopathy, two were chronic liver disease with cirrhosis and portal hypertension and one was tuberculosis. The perinatal outcomes in other miscellaneous causes of jaundice are shown in Table 3 .

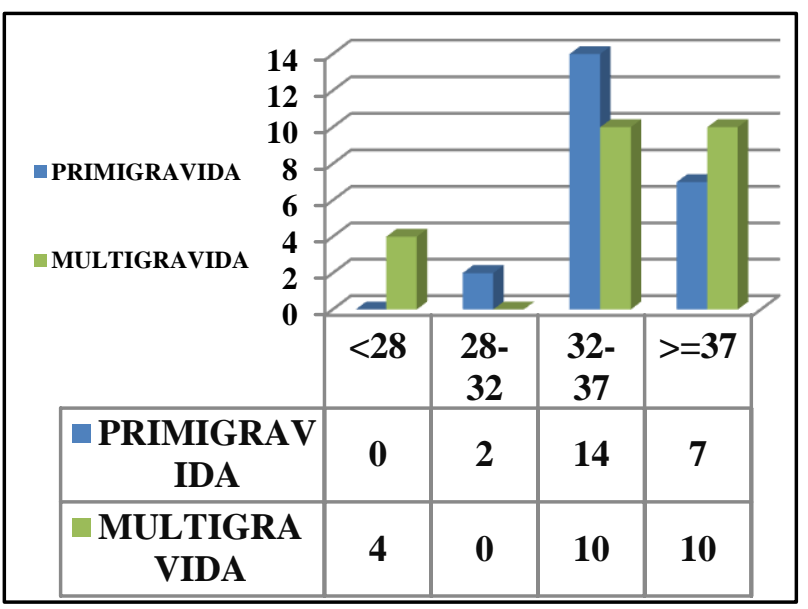

Figure 5: Births and weeks of gestation.

Table 3: Perinatal outcome.

\begin{tabular}{|c|c|c|}
\hline Outcome & $\begin{array}{l}\text { Number of } \\
\text { patients }\end{array}$ & $\begin{array}{l}\text { Patients } \\
\%\end{array}$ \\
\hline Live births & 36 & 67 \\
\hline IUGR neonates & 18 & $50 \%$ \\
\hline Meconium stained babies & 13 & $36 \%$ \\
\hline Still births & 12 & $22 \%$ \\
\hline Macerated still births & 3 & \\
\hline Fresh still births & 9 & \\
\hline Undelivered & 5 & $9 \%$ \\
\hline Abortus & 1 & $2 \%$ \\
\hline $\begin{array}{l}\text { Birth weight }<2.5 \mathrm{~kg} \\
\text { (all births) }\end{array}$ & 33 & $70 \%$ \\
\hline Birth weight $>2.5 \mathrm{~kg}$ & 14 & $30 \%$ \\
\hline Neonatal death & None & \\
\hline Nicu admission & $\begin{array}{l}\text { of } 36 \\
\text { rths }\end{array}$ & $\begin{array}{l}50 \% \text { (of } \\
\text { otal births) }\end{array}$ \\
\hline Causes & Out of 18 & \\
\hline Low birth weight & 12 & $66 \%$ \\
\hline Severe IUGR & 2 & $11 \%$ \\
\hline $\begin{array}{l}\text { Meconium aspiration } \\
\text { syndrome }\end{array}$ & 5 & $28 \%$ \\
\hline \multicolumn{3}{|c|}{ Fetal outcomes in other causes of jaundice } \\
\hline Gilberts syndrome & \multicolumn{2}{|c|}{ Full term live birth } \\
\hline Falciparum malaria & \multicolumn{2}{|c|}{ Full term live birth } \\
\hline Leptospirosis & \multicolumn{2}{|c|}{ Abortus } \\
\hline $\begin{array}{l}\text { Cirrhosis with portal } \\
\text { hypertension with } \\
\text { oesophageal varices (2), } \\
\text { Drug induced (1) }\end{array}$ & \multicolumn{2}{|c|}{ Died undelivered } \\
\hline HELLP syndrome & \multicolumn{2}{|c|}{ Preterm still birth } \\
\hline
\end{tabular}

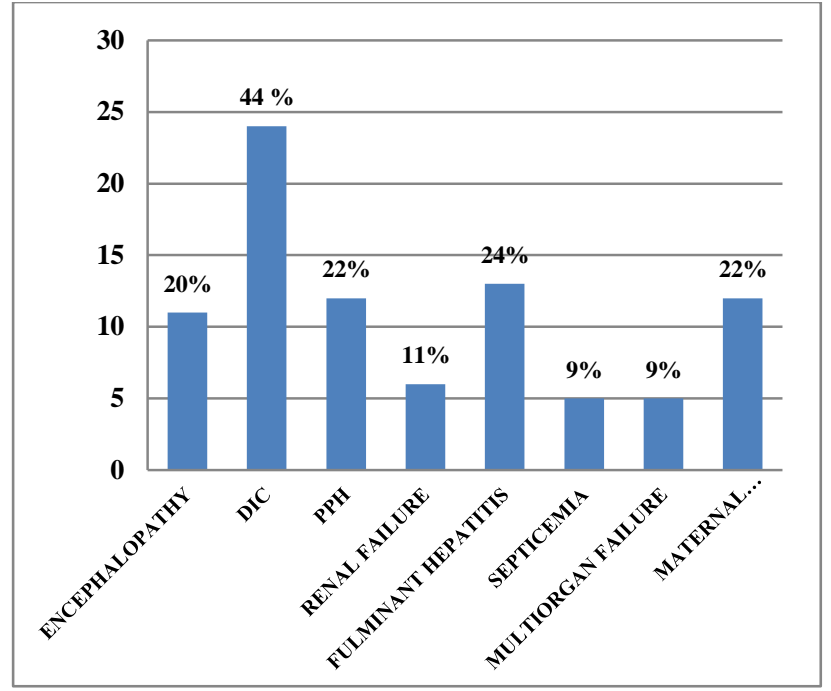

Figure 6: Maternal complications.

The maternal complications seen most commonly were disseminated intravascular coagulation, postpartum haemorrhage, encephalopathy and fulminant hepatic failure. Subsequently, multi organ failure developed in $9 \%$ of patients due to underlying complications like DIC and postpartum haemorrhage. The distribution is shown in Figure 6.

Maternal morbidity due to jaundice was significant. Intensive care was given to 18 patients, out of which 13 patients were hepatitis E positive. Ventilator support was required in $73 \%$ of the patients admitted to the intensive care unit. As most common complication associated with jaundice is disseminated intravascular coagulation due to poor liver function, blood and blood products transfusion is required in most patients. Our hospital being a tertiary care centre with a well-equipped blood bank, this necessary facility was provided to all the patients who needed the same. Table 4 shows the maternal morbidity associated with jaundice.

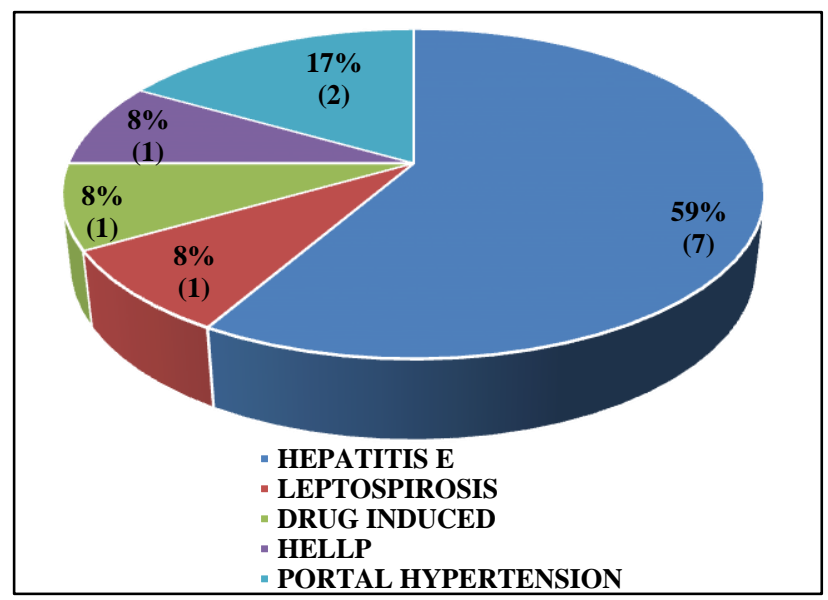

Figure 7: Causes of maternal mortality. 
Twelve patients succumbed to the disease accounting to $22 \%$ of the maternal mortality in our institution. The causes of maternal mortality being DIC with haemorrhage and shock, multi organ failure, septicemia and hepatic encephalopathy due to fulminant hepatic failure. Hepatitis E alone was accountable for 7 out of the 12 deaths (59\%). Figure 7 shows the various causes of maternal deaths. Two were due to pre-existing chronic liver disease with portal hypertension which got aggravated during pregnancy and the patients succumbed to multi organ failure and DIC. One patient died of Leptospirosis, one due to HELLP syndrome and one due to drug induced hepatic failure at 28 weeks gestation. She was on anti-tubercular therapy for Koch's abdomen diagnosed two months prior to admission started on first line of anti-tubercular drugs. She was admitted with severe jaundice, ascites and hepatic coma. She died undelivered due to respiratory failure.

\section{DISCUSSION}

Jaundice in pregnancy is a high risk pregnancy and requires a tertiary centre care for management of the same and prompt management of maternal complications. The incidence of jaundice in pregnancy from our study was $0.81 \%$. This is comparable to results as cited by Kamalajayaram and Devi $\mathrm{R}$ et al who stated it as $0.46 \%{ }^{5}$ The figure is higher in our study as our hospital is a tertiary care centre and the patient load is large. The most common cause of jaundice was viral hepatitis accounting for $62 \%$ of the cases. The similar finding was noted by Nagaria and Mitra A et al, Jan et al, Shukla et al found that the incidence of viral hepatitis causing jaundice was $57 \%$ while Ching et al reported half of patient out of 48 were of viral hepatitis in pregnancy. ${ }^{6-10}$

Hepatitis $\mathrm{E}$ is the most prevalent and most dangerous type of viral hepatitis, contributing to $71 \%$ of the cases of viral hepatitis in our case series. The incidence reported by a study done by

ICMR is as high as $80-90 \%$ in cases of viral hepatitis in pregnancies. Totally, hepatitis E contributed to $44 \%$ cases of jaundice. Hepatitis $\mathrm{E}$ is a self-limiting enterically transmitted acute viral hepatitis. In non-pregnant women the disease has a case fatality rate of $<0.1 \%$. However in

Pregnant women mortality may be as high as $25 \%$; as in our series it was seen to be $29.1 \%$. The course of events in other viral causes of hepatitis and that of hepatitis $\mathrm{E}$ differs in the fact that hepatitis $\mathrm{E}$ has a more fulminant course in pregnancy. Pregnancy appears to be a potential risk factor for viral replication and extreme low immune status of Indian or rather Asian pregnant women. ${ }^{11}$ The reason for this phenomenon is unclear, yet certain reasons have been put forward to prove the same. There is a shift in the T Helper cell balance in pregnancy more towards a $\mathrm{TH} 2$ response leading to reduced $\mathrm{CD} 4$ and increase in CD8 count thus causing a moderate amount of immunosuppression. This is superadded to the immunosuppressed state of pregnancy. Also, estrogen and progesterone secreted in high amounts during pregnancy impair the cell mediated immunity by triggering the adapter protein of HEV virus (ORF3) which also facilitates replication of the virus and further catastrophe. $^{12}$

$55 \%$ of pregnant women in our study developed complications like DIC, septicemia, and multi organ failure including fulminant hepatitis, which was in turn more commonly seen in third trimester in hepatitis $\mathrm{E}$ patients, with high maternal mortality ranging from 15 $45 \%$. There were totally 78 maternal deaths in our institution during the study period, 12 maternal deaths due to jaundice $(15.3 \%)$. Case fatality rate of jaundice in pregnant woman is $21.8 \%$.

Seven maternal deaths were due to hepatitis E. The other causes have been depicted pictorially.

The perinatal mortality from our study was $22 \%$ (12 still births in 55 cases); out of which 9 were fresh still births and 3 were macerated still births, with no neonatal deaths.

The second most common cause of jaundice in pregnancy from our study was cholestatic jaundice which accounted for $23.6 \%$ of the cases. Pruritus is the most common complaint in these patients. Pruritus with elevated serum bile acids seen in second half of pregnancy resolving soon after delivery is considered as intrahepatic cholestasis. The recurrence of this complication is frequently seen in subsequent pregnancies. Since maternal morbidity associated with it is low, the effects are seen on the fetus. Our findings are similar to the findings reported by Dhawan and Sainani. ${ }^{13}$ Ching et al reported 5 out of 48 cases of intrahepatic cholestasis in pregnancy. ${ }^{10}$ All the cases of intrahepatic cholestasis of pregnancy were observed in the third trimester of pregnancy similar to the study by Ch'gh et al in South Wales. ${ }^{14}$ Hemolysis, elevated liver enzymes and low platelet count, known as HELLP syndrome is a grave condition that affects $0.1-0.6 \%$ of all pregnancies. Although it is considered a complication of preeclampsia, only $4-12 \%$ of women with severe preeclampsia experience HELLP syndrome.

In our study we had three patients of HELLP. Ching et al reported 2 cases out of 48 of HELLP syndrome in pregnancy. ${ }^{10}$ Two patients recovered uneventfully and one patient died due to disseminated intravascular coagulation. All three patients had poor perinatal outcome as preterm still births. Perinatal death in this condition is due to very early gestational age in the setting of severe IUGR or abruption placenta. Complications of HELLP include DIC, abruption placenta, acute renal failure, pulmonary edema and rarely hepatic rupture. 
All patients with jaundice were given special treatment. Bed rest and diet comprised the main factors in the management of these patients. A nutritious diet containing about $3000 \mathrm{Kcal}$ daily was provided. High protein diet was recommended. Critically ill patients were admitted in intensive care unit and parenteral nutrition was given. Broad-spectrum antibiotics, mainly third generation cephalosporin's (which were not hepatotoxic) and metronidazole were given to prevent sepsis. Blood and blood products transfusion was required in $55 \%$ of the cases who had an abnormal coagulation profile. All patients with coagulopathy and acute liver failure were administered $\mathrm{N}$ acetyl cysteine (NAC). It acts as a glutathione precursor and has an anti-oxidant and vasodilating properties. Improvements in the consumption of oxygen and oxygen extraction ratio have been observed through various studies by intravenous administration of NAC. Ursodeoxycholic acid (UDCA) was given to all the patients as it improves pruritus. In obstetric cholestasis, the proposed mechanism of action of UDCA is displacement of more hydrophobic endogenous bile salts from the bile acid pool. This may protect the hepatocyte membrane from the damaging toxicity of bile salts; enhance bile acid clearance across the placenta from the fetus. ${ }^{15}$

\section{CONCLUSION}

Jaundice with pregnancy is a bad combination. It affects a small percentage of pregnant women, yet takes a major toll on two lives the mother and the fetus. In a country like India, beginning from health education to the pregnant mother regarding warning signs and immediate visit to the doctor, to medical personnel at primary health centre for early transfer can go long way in lowering maternal and perinatal mortality and morbidity due to jaundice in pregnancy. Lastly, a team collaboration of obstetrics, internal medicine, gastroenterology, and anaesthesia and critical care is very much essential to combat the grave complications of this condition and to achieve a fruitful outcome.

\section{Funding: No funding sources}

Conflict of interest: None declared

Ethical approval: The study was approved by the Institutional Ethics Committee

\section{REFERENCES}

1. Karegoudar D, Patel RD, Dhital M, Amgain K. A study of liver disorder and its consequences in pregnant women with jaundice in tertiary care centre in Belgaum, Karnataka, India. IOSR Journal of Dental and Medical Sciences. 2014;13(5):14-8.

2. Tripti N, Sarita A. Fetomaternal outcome in jaundice during pregnancy. Obstet Gynecol of India. 2005;55(5):424-7.

3. Khuroo MS. Hepatitis E: the enterically transmitted non-A, non-B hepatitis. J Gastroenterol. 1991;10:96100.

4. D'Souza AS, Gupta G, Katumalla FS, Goyal S. Maternal and fetal outcome in liver diseases of pregnancy: a tertiary hospital experience. International Journal of Scientific and Research Publications. 2015;5(9):1-4.

5. Kamalajayaram V, Devi RA. A study of maternal morbidity and mortality in jaundice. Journal of Obstetrics and Gynaecology of India. 1988;38:43941.

6. Nagaria T, Agarwal S. Fetomaternal outcome in jaundice during pregnancy. J Obstet Gynecol India. 2005;55:424-7.

7. Mitra AK, Patki PS, Mitra SK. Liver disorders during pregnancy and their management. The Antiseptic. 2008;105(4):193-6.

8. Jan Y, Bilques S, Najmi AM, Qureshi MA, Khan SS, Rafiq $M$, et al. Viral hepatitis during pregnancy: a study of its socio- clinical profile in a tertiary care hospital. J Dental and Med Sci. 2012;3(2):18-22.

9. Shukla S, Mehta G, Jais M, Singh A. A prospective study on acute viral hepatitis in pregnancy; seroprevalence and fetomaternal outcome of 100 cases. J Biosci Tech. 2011;2(3):279-86.

10. Ching LY, Barge N, Dalal AR. Study of jaundice in a tertiary care institution in India. Bombay Hospital J. 2011;53:181-3.

11. Hin HK. Acute fatty liver of pregnancy. Canadian $\mathbf{J}$ Gastroenterol. 2006;1:25-30.

12. Nayak NC, Panda SK, Datta R, Zuckerman AJ, Guha DK, Madanagopalan N, et al. Aetiology and outcome of acute viral hepatitis in pregnancy. J Gastroenterol Hepatol. 1989;4:345-52.

13. Dhawan PS, Sainani GS. Diagnosis of liver disorder in pregnancy. Am $\mathrm{J}$ Obstetrics and Gynaecology. 1996;23:609-13.

14. Ch'ng CL, Morgan M, Hainsworth I, Kingham JGC. Prospective study of liver dysfunction in pregnancy in Southwest Wales. Gut. 2002;51:876-80.

15. Serrano MA, Rites D, Larena MG, Monte MJ, Bravo MP, Oliviera $\mathrm{N}$, et al. Beneficial effect of ursodeoxycholic acid on alterations induced by cholestasis of pregnancy in bile acid transport across the human placenta. J Hepatol. 1998;28:829-39.

Cite this article as: Satia MN, Jandhyala M. A study of fetomaternal outcomes in cases of jaundice at a tertiary care centre. Int J Reprod Contracept Obstet Gynecol 2016;5:2352-7. 